\title{
Analysis of the Cooling Effect of Urban Green Spaces in Mitigating Micro-climate Change Using Geospatial Techniques in Adama City, Central Ethiopia
}

Biratu Bobo Merga ( $\sim$ bira2bobo@gmail.com )

Oda Bultum University https://orcid.org/0000-0002-7249-7576

Kenate Worku Tabor

Girma Alemu

\section{Research Article}

Keywords: Cooling Efficiency, Land Surface Temperature, Micro-Climate, Normalized Difference Built-up Index, Normalized Difference Vegetation Index

Posted Date: December 30th, 2021

DOI: https://doi.org/10.21203/rs.3.rs-1095929/v1

License: (c) (i) This work is licensed under a Creative Commons Attribution 4.0 International License.

Read Full License 


\section{Cover letter}

22 November, 2021

\section{To: Theoretical and applied Climatology}

Dear editor-in-chief of Journal of Theoretical and applied Climatology, I would like to submit the manuscript entitled as "Analysis of the cooling effect of urban green spaces in mitigating micro-climate change using geospatial techniques in Adama City, Central Ethiopia" for publication to your journal. The manuscript is an original article which is not published elsewhere. The manuscript is prepared to the standard of your journal and which will contribute for scientific communities.

Biratu Bobo Merga

Oda Bultum University 
Analysis of the Cooling Effects of Urban Green Spaces in Mitigating Micro-climate Change Using Geospatial Techniques in Adama City, Central Ethiopia

Authors' Information

${ }^{1 *}$ Biratu Bobo Merga; ${ }^{2}$ Kenate Worku Tabor; ${ }^{3}$ Girma Alemu

1* Department of Geographic Information Science, Institute of Land Administration, Oda Bultum University

${ }^{2}$ Department of Geography and Environmental Studies, Collage of Social Science and Humanities, Jimma University

${ }^{3}$ Department of Geography and Environmental Studies, Collage of Social Science and Humanities, Jimma University

Corresponding author: Name: Biratu Bobo Merga

E-mail: bira2bobo@gmail.com

Phone no: +251921 184447

ORCID ID: $\underline{\text { https://orcid.org/0000-0002-7249-7576 }}$ 


\section{ABSTRACT}

Nowadays, addressing urban climate in urban planning through mapping has got world-wide attention. Greening urban environment is one of the best mechanisms to combat the effects of micro-climate change. Therefore, this study aims at analyzing the cooling effects of Urban Green Spaces (UGS) in mitigating micro-climate change in Adama City with special emphasis on land surface temperature variation with respective to vegetation cover for the last two decades i.e. from 2000 to 2020. Three different remotely sensed data of Landsat7 ETM+ (2000 and 2010) as well as Landsat8 OLI/TIRS (2020) were used in the study. The consistent land surface temperature data were retrieved from Landsat7 ETM+ and Landsat8 OLI/TIRS using mono window and split window algorithms, respectively. Regression and correlation analysis among Land Surface Temperature (LST), Normalized Difference Vegetation Index (NDVI) and Normalized Difference Built-up Index (NDBI) were also performed in Statistical Package for Social Science (SPSS V23). The study reveals that the proportion of Urban Green Spaces (UGS) to other land uselland cover particularly, dense vegetation cover were reduced from $29.3 \mathrm{Km}^{2}(21.20 \%)$ in 2000 to $18.17 \mathrm{Km}^{2}$ (13.15\%) in 2020. The main land dynamic process, which could considerably contribute to the increase in Land Surface Temperature, was the rapid expansion of built-up areas in the study area. The model produced through multiple linear regression analysis clearly indicates that the two urban parameters (built up and green areas) contributed $75.2 \%$ of the Land Surface Temperature (LST) variations in Adama City. The cooling efficiency (CE) and the threshold value of efficiency (TVoE) of green space in Adama City were calculated as $5.5 \pm 0.5$ ha. This finding implies that when Adama City municipality implements urban planning, allocating a green space area of $5.5 \pm 0.5$ ha reduces surface temperature by about $2.85{ }^{\circ} \mathrm{C}$ which is the most efficient to reduce heat effects. The study suggests that strengthening of plan execution capacity, public participation in urban planning and strengthening the development of urban green spaces as an important strategy to mitigate the effects of micro-climate change.

Key Words: Cooling Efficiency: Land Surface Temperature; Micro-Climate; Normalized Difference Built-up Index; Normalized Difference Vegetation Index 


\section{Introduction}

Earth's surface temperature is a product of the balance between incoming solar energy and outgoing radiation energy (Roza et al., 2017). The warmer the earth gets, the more the energy it radiates out. Earth is being experiencing a warmer atmosphere since the pre-industrial era and contributed to a significant increase in the global mean temperature (IPCC, 2014).

Urban Heat Island (UHI) is a result of rapid urbanization which is described as urban areas with significantly warmer temperature than its nearby rural areas (Kong, 2016). There are a number of contributing factors which play significant role in the formation of UHI; for instance low albedo materials, air pollutant, wind blocking, clearance of trees and increased use of air conditioner (Nuruzzaman, 2015).

Fast urbanization leads to reduction of vegetation areas; and increases land surface temperature and consequently changes urban micro-climate (Nor et al., 2013). Increased replacement of natural green areas to urbanized areas, diminishing of agricultural lands, expansion of impervious surfaces, extensions of barren land because of the built-up areas have led to significant changes in the local climate conditions. Due to all these factors temperature distribution in urban areas is expressively warmer than its surrounding sub-urban areas (Senanayake et al., 2013).

As one of the basic elements of the urban environment, urban green space is the only type of land use with natural or semi-natural conditions inside a city; and plays a significant role in protection of the ecological environment of cities (Ngom et al., 2016). Vegetation is a vital element of global environment. It modifies the ecosystem through water preservation, terrestrial soil constancy and atmospheric circulation. It also helps to sustain a balance of ecosystem prominently. Urban greenery also acts as a natural agent against air pollution in the urban environment (Buyadi et al., 2015).

Trees and green spaces contribute considerably to the improvement of the urban climate and to the UHI mitigation. Decrease of the temperature is achieved through trees that provide solar protection, affect air movements and heat exchange, absorb solar radiation and cool the air through evapotranspiration processes. It should be noted that urban parks may extend their cooling potential and decrease ambient temperatures in adjacent urban zones depending on the 
thermal balance of the overall area under study. Urban parks provide thermal comfort and a high mitigation potential (Cohen et al., 2013). Because of transpiration, greenery plays a significant role in alleviating UHIs by dropping temperature and increasing humidity. Their cooling effects are especially important; and they have been regarded as natural resources for city planning (Sandra et al., 2011).

The role of green spaces in mitigating urban heat island in some cities of the country have been widely studied, for example, Feyisa, 2014; Ermias and Hewot, 2018; and Samson et al, 2018, documented the effects of urban green spaces on climate. However, these are among the very few of the studies implemented in Adama City, Central Ethiopia. In these studies, the contribution of each and every green space patches in minimizing surface temperature has not received considerable attentions. We still lack understanding of the relationship between Land Surface Temperature (LST) and green spaces which limits the ability to make specific recommendations for urban land use optimization, as well as the ability of landscape planning and design to mitigate the heating effects within the city.

Therefore, this study aimed at assessing the cooling effect of green space on Land Surface Temperature (LST) using geospatial techniques. Findings from the study will provide an understanding of the Land Surface Temperature (LST), Urban Heat Island (UHI) and LU/LC status of the area as an input for planning and decision-making. Therefore, the purpose of the study was to analyze the cooling effects of green spaces to generate valuable information to provide an understanding of the Land Surface Temperature (LST), Urban Heat Island (UHI) and LU/LC status of the area as an input for planning and decision-making.

\section{Materials and Methods}

\subsection{The Study Area}

This study was conducted in Adama City, which is located in the Great Ethiopian Rift Valley; and found at about $100 \mathrm{Km}$ Southeast of Addis Ababa, Ethiopia. Adama city has hot and dry weather for the greater part of winter and warm and sunny in summer. It lies in Great Rift Valley of East Africa; and the altitude of the central part of the city constitutes the lowest area.

As part of developing countries' cities, Adama City is also facing high rate of land use/land cover change due to urban development activities. Due to the increase of population, 
industrialization and other natural and human activities, land use/land cover of the city is changing. Transformation of agricultural lands into urban areas has greatly affected the land components and the environment. Consequently, the natural vegetation in and around the city is also converted into impervious surface. Expansion led by government and private sectors mainly mass housing program like condominiums, single residential and real state constructions and other developmental activities such as construction of roads and factories are visible evidence for the eradication of green spaces in the city. Its absolute location stretches between $8^{0} 27^{\prime} 00^{\prime \prime}$ to $8^{0} 36^{\prime} 00^{\prime \prime}$ North latitude and $39^{\circ} 12^{\prime} 30^{\prime \prime}$ to $39^{\circ} 20^{\prime} 30^{\prime \prime}$ East longitude and covering a total area of $138.2 \mathrm{~km}^{2}$ (Figure 1).

According to CSA, 1994; CSA, 2007; and Survey made by Adama City Statistics Bureau in 2012/2013 the city has a total population of 127842, 220212 and 282976, respectively (Figure 2).

There are four climatic seasons; Kremt (rainy period) Bega (dry period) Belg (small rains) and Meher (a spell between the long and small rain periods). The city experiences the hottest and coldest temperature during May and December respectively. On the average, rainy season is June, July, August and September; whereas, the dry month is in January, October, November and December. Among all months, the driest month is December. According to Central Statistical Agency (CSA) and Survey made by Adama City Statistics Bureau in 2012/2013 the city has a total population of 282,976 .

\subsection{Data Types and Sources}

Data for the study was collected from both primary and secondary sources. Primary data source includes observations and field works. Observation was made to collect ground truth points for validation of Land Use/Land Cover (LU/LC) classes as well as different photographs were taken for further identification of each LU/LC of the study area. These were carried out in order to identify the land use land cover classes such as built up, open spaces, water bodies and the spatial distribution of green spaces. Secondary data sources include reviewing of different relevant literatures of the specific study area and related studies.

Two sets of remotely sensed data such as Landsat7 ETM+ of the year 2000 and 2010 and Landsat8 OLI/TIRS of the year 2020 were used (Table 1). The obtained images were free from cloud or haze. Temperature data and Shapefile of the City were also used for this study (Table 2). 
Results were then used to analyze relationships between LST and NDVI using spatial regressions between each LST image and the NDVI image.

\subsection{Data Processing and Analysis Methods}

\subsubsection{Land Use/Land Cover Classification}

Image processing was employed using ERDAS IMAGINE V15 software. Supervised classification approach was applied to classify the year 2000, 2010 and 2020 images with a maximum likelihood classifier algorithm (MLC). MLC is one of the eminent parametric classifiers used for supervised image classification (Foody et al., 1992). It is one of the most known methods of classification in remote sensing, in which a pixel with the MLC is classified into the matching classes/categories. It is a statistical decision measure to assist in the classification of overlapping signatures; pixels are assigned to the class (categories) of the highest probability. It was considered more accurate than parallelepiped classification. The MLC classification tool considers both the variances of the class signatures when assigning each cell to one of the classless represented in the signature file.

Post classification smoothing has also been done on the LU/LC to remove noisy pixels. Sample data from the field using GPS and visual interpretation of the selected land use/land cover class were prepared; and then land cover polygons were made using ArcGIS 10.5 to extract and reclassify the urban green spaces. Finally, urban green land cover classes were identified and mapped for further analysis.

Finally, accuracy assessment was performed to evaluate the quality of classification output. Error matrix based on assessment of the overall accuracy; producer's accuracy, user's accuracy, and kappa coefficient were utilized to evaluate the pixel-based classification output for LU/LC classification. The purpose of accuracy assessment is to quantitatively assess how efficiently the pixels were tested into the correct land cover classes (Bhatta, 2008).

\subsubsection{Retrieval of Land Surface Temperature (LST)}

Land surface temperature is defined as the radiative temperature of the land surface and usually LST is measured by remote sensing whereas air temperature is measured $1-2 \mathrm{~m}$ above the ground using instrumentation technique. Near surface air temperature is a consequence of complex 
effects of the turbulent heat transports produced by nearby heated surfaces (Avdan et al., 2016). To retrieve LST for the study area, mono window algorithm for Landsat7 and split window algorithm for Landsat 8 were employed.

Mono window algorithm is an algorithm which possesses the benefits of easy determination of parameters, extensive applications (Yu et al., 2014), and high precision reversal which could accurately reflect regional land surface heat distribution (Eq. 1).

$$
\begin{aligned}
& \text { Ts }=\{\mathrm{a} 6(1-\mathrm{C} 6-\mathrm{D} 6)+(\mathrm{b} 6(1-\mathrm{C} 6-\mathrm{D} 6)+\mathrm{C} 6+\mathrm{D} 6) \mathrm{T} 6-\mathrm{D} 6 \mathrm{Ta}\} / \mathrm{C} 6 \\
& \mathrm{C} 6=6 \tau 6 \\
& \mathrm{D} 6=(1-\varepsilon 6)[1+(1-\varepsilon 6) \tau 6]
\end{aligned}
$$

Where; T6 is brightness temperature, $\varepsilon 6$ is land surface emissivity, $\tau$ is atmospheric emissivity in thermal infrared and $\mathrm{Ta}$ is an average atmospheric temperature which can be calculated by parameter estimation method of the mono-window algorithm (Qin et al., 2003). Also, a6 = 67.355351, b6 $=0.458606$, C6 and D6 are intermediate variables and Ts is the Land Surface Temperature (LST) to be calculated.

Split-window algorithm is used to retrieve land surface temperature from Landsat 8 data that has two bands (Band 10: 10.6 $\mu \mathrm{m}$ to $11.2 \mu \mathrm{m}$, Band 11: $11.5 \mu \mathrm{m}$ to $12.5 \mu \mathrm{m}$ ). Split-window algorithm uses brightness temperature of the two bands of Thermal Infrared (TIR), mean and difference in land surface emissivity for estimating LST. The process of acquiring LST values follows conversion of thermal infrared Digital Numbers (DNs) (Bands 10 and 11) to radiance Top of Atmosphere (TOA) and at-satellite brightness temperature.

The effective at-sensor Brightness Temperature (BT) is also known as black body temperature which was obtained from the spectral radiance using Plank's inverse function. Spectral radiance values for bands 10 and 11 were converted to radiant surface temperature under an assumption of uniform emissivity using pre-launch calibration constants for the Landsat 8 OLI sensor. After spectral radiance is converted to radiance, the raw digital numbers of the thermal bands are converted to Top of Atmosphere (TOA) brightness temperatures, which are the effective temperature viewed by the satellite under an assumption of emissivity (Chander et al., 2009) (Eq. 2). 
$\mathrm{LST}=\mathrm{TB} 10+\mathrm{C} 1(\mathrm{~TB} 10-\mathrm{TB} 11)+\mathrm{C} 2(\mathrm{~TB} 10-\mathrm{TB} 11) 2+\mathrm{Co}+(\mathrm{C} 3+\mathrm{C} 4 \mathrm{~W})(1-\Delta \mathcal{E})+(\mathrm{C} 5+\mathrm{C} 6 \mathrm{~W}) \Delta \mathcal{E}$

Where; C0, C1, C2, C3, C4, C5 and C6 is the split-window coefficients; TB10 is brightness temperature of band 10 (Kelvin K); TB11 is brightness temperature of band 11 (Kelvin K); $\mathcal{E}$ is mean value of Land Surface Emissivity (LSE) of TIR bands; W content of water vapors in the atmosphere; $\Delta \mathcal{E}$ is difference between LSE of bands 10 and 11 emissivity, and then to estimate $\operatorname{LST}($ Eq. 3);

$$
\mathrm{BT}=\frac{K 2}{\ln \left(\frac{K 1}{L \lambda}+1\right)}
$$

Where; BT is effective at-sensor brightness temperature $(\mathrm{K})$; K2 is calibration constant $2(\mathrm{~K})$; $\mathrm{K} 1$ is calibration constant $1\left(\mathrm{~W} /\left(\mathrm{m}^{2} * \mathrm{sr} * \mu \mathrm{m}\right)\right)$; $\mathrm{L} \lambda$ is spectral radiance at sensors aperture (W/ $(\mathrm{m} 2 * \mathrm{sr} * \mu \mathrm{m})) ;$ and $\mathrm{Ln}$ is a natural logarithm.

To compute Land Surface Emissivity (LSE), it is essential to know the characteristics of the earth's surface and change the thermal radiance energy during calculation of LST (Sobrino et al., 2012). According to Sobrino et al. (2004), the emissivity is calculated using (Eq. 4);

$$
\varepsilon=0.004 * \mathrm{PV}+0.986
$$

Where; PV is Vegetation Proportion (Eq. 5).

$$
P V=\left[\frac{\text { NDVI-NDVImin }}{\text { NDVImax }- \text { NDVImin }}\right]^{2}
$$

NDVI is Normalized Difference Vegetation Index; whereas, NDVI max is Maximum Normalized Difference Vegetation Index and NDVI min is minimum Normalized Difference Vegetation Index.

The calculated radiant surface temperature is corrected for emissivity using the equation (Eq. $6)$;

$$
\mathrm{LST}=\frac{\mathrm{TB}}{1(\lambda \mathrm{TB} / \mathrm{P}) \operatorname{In} \varepsilon}
$$


Where; LST is Land Surface Temperature, TB is radiant surface temperature in $(\mathrm{K}), \lambda$ is the wave-length of emitted radiance $(11.5 \mu \mathrm{m}), \rho$ is constant $\left(6.26 * 10^{-34} \mathrm{~J} \mathrm{~s}\right)$; and $\varepsilon$ is land surface emissivity.

\subsubsection{Extraction of Built-Up Index}

The Normalized Difference Built-up Index (NDBI) is often mixed with plant noise. NDBI values range from -1 to 1 . The greater the NDBI is, the higher the proportion of built-up land is, (Varshney, 2013). NDBI is derived from Landsat ETM and Landsat 8, from reflectance measurements in the red and mid-infrared (MIR) portion of the spectrum. The NDBI value is obtained using the following equation and applied to identify urban built area (Eq. 7).

$\mathrm{NDBI}=\frac{\mathrm{MIR}-\mathrm{NIR}}{\mathrm{MIR}+\mathrm{NIR}}$

Where; MIR is Mid Infrared (Band 6 for Landsat 8) and NIR is Near Infrared (Band 5 for Landsat 8) (Zhou et al., 2014).

\subsubsection{Extraction of Normalized Difference Vegetation Index (NDVI)}

The spatial distribution of urban green spaces in Adama city was extracted and analyzed on the basis of the value of NDVI. The values of NDVI generally range between -1 to +1 . The -1 value depicts the absence of vegetation and +1 value shows the presence and density of vegetation. Moreover, NDVI values are suitable for the calculation of change detection analysis. Very low value of NDVI ( 0.1 and below) correspond to barren areas of rock, sand, or snow (Chen et al., 2006; Buyand et al., 2015; Pervaiz et al., 2018).

The values of NDVI can further categorized as non-vegetated for the value $<0$, unhealthy vegetation for the value between $0.02-0.03$ and moderate values represent bush and grasses $(0.2$ to 0.3), whereas, high NDVI value correspond to dense vegetation (0.6 to 0.8) (Gandhi, 2015). These activities was computed and analyzed in ArcGIS Software environment (Eq. 8).

$$
\mathrm{NDVI}=\frac{\mathrm{NIR}-\mathrm{R}}{\mathrm{NIR}+\mathrm{R}}
$$

Where; NIR is a Near Infrared (the pixel Digital Number (DN) of TM Band 4 and Band 5 for Landsat 7 and 8 respectively); and $\mathrm{R}$ is Red Band (Band 3 and Band 4 for Landsat7 and 8 respectively) (Gandhi, 2015). 


\subsubsection{Determination of Green Spaces' Cooling Effect}

To determine the contribution of green spaces in mitigating UHI, each green space patches was extracted with corresponding LST values for the identified year. In consideration of the possible varying temperature conditions, the temperature of each LU/LC classes in relation to the entire landscape was computed separately. With the mean temperature within the study area as baseline, the thermal influence of each LU/LC types to the entire urban landscape was computed by the Contribution Index (CI) (Chen et al., 2006) using function (Eq. 9).

$\mathrm{CI}=\mathrm{D} * \mathrm{St}$

Where: CI is Contribution Index i.e. the influence of each green space patch to the entire landscape, D is the difference in mean temperature between the zones (green space patches) and the entire urban landscape; and $\mathrm{St}$ is the proportion of the area to the entire landscape.

The Green Index (GI) percentage of green space patches was calculated based on binary classification (green and non-green classes) of NDVI measurements. The negative values of NDVI measurement is classified as built up area and positive values are classified as green class (Kshama, 2012).

Green space cooling effect is determined as the difference in temperature between inside the green space and the average land surface temperature of the entire landscape (Choi et al., 2010). To determine the cooling effects of green spaces, surface temperature of green spaces and the entire land scape should be computed (Eq. 10).

$\Delta \mathrm{T}=\left(\mathrm{T}_{\mathrm{u}}-\mathrm{T}_{\mathrm{p}}\right)$

Where: $\Delta T$ is Change in Land Surface Temperature, $T_{p}$ is the average LST of green space; and $\mathrm{T}_{\mathrm{u}}$ is the average LST of the entire landscape.

\subsubsection{Software Used for the Study}

For the achievement of the study's purpose, different software required is stated as table below (Table 3). 


\section{Results}

\subsection{Land Use/Land Cover (LU/LC) map of the period 2000 to 2020}

The LU/LC of the year 2000 shows that the city had built up area (buildings and uncovered soil) with total area of $31.75 \mathrm{~km}^{2}(22.97 \%)$ and dense and sparse vegetation cover with total area of $102.26 \mathrm{~km}^{2}(74 \%)$ respectively. However, these green spaces became rapidly eradicated and replaced by built-up areas. Among the five major LU/LC classes, built-up areas which are shown in pink color (Figure 4C) rank $1^{\text {st }}$ in terms of size and percentage of land cover classes from 2010 to 2020. It is rapidly increasing with corresponds to the context of rapid urbanization in Adama City. Dagnachew, (2018) also pointed out that built-up areas consume considerable amount of land from vegetation cover during urban development. The proportion of Urban Green Spaces (UGS) particularly, dense vegetation which includes indigenous forest and thicket were reduced from $29.3 \mathrm{Km}^{2}(21.20 \%)$ in 2000 to $18.17 \mathrm{Km}^{2}(13.15 \%)$ in 2020 , whereas built up area was increased from $31.75 \mathrm{~km}^{2}(22.97 \%)$ to $86.0 \mathrm{~km}^{2}(62.24 \%)$. Built-up areas occupy the dominant LU/LC classes which is the most significant change in land cover classes' proportion (Figure 5).

Though built-up area is one of the most important causes for the rise of land surface temperature, greeneries in the individual housing area has high impact on the LST distribution. Even if the central part of the city is occupied by large portion of built-up areas, it experiences relatively low mean surface temperature. This is mainly resulted from the availability of greeneries that are found in public facilities which is purposively planted for shading. The maximum mean LST were registered on peripherals. The high rate of activities in manufacturing and transport sector along with power generation in these areas can also be the major possible cause for an acceleration of the mean of LST in Adama City.

\subsection{Land Surface Temperature Analysis}

Land Surface Temperature (LST) distribution was classified into appropriate ranges and colorcoded to generate a thermal pattern distribution map of the study area. A result of this study shows that different LU/LC classes have different LST values. Analysis from Landsat images ETM+ that acquired on 18 January, 2000; February 11, 2010 and Lansat8 OLI/TIRS which obtained on January 05, 2020 clearly indicate that surface temperature of Adama City has increased from $28.25^{\circ} \mathrm{C}$ in 2010 to $31.78^{\circ} \mathrm{C}$ in 2020 . 
Extreme LST values were found in bare lands (vacant spaces) and built-up areas. This finding clearly shows that both bare land and built-up areas are the two major possible causes for the rise of surface temperature in the study area. An area that covers $8.23 \mathrm{~km}^{2}(5.95 \%)$ that had LST values of $30^{\circ} \mathrm{C}-34^{0} \mathrm{C}$ in 2000 was increased in to $38.97 \mathrm{~km}^{2}(28.20 \%)$ in 2020 (Table 4).

Man-made features like road construction and other buildings could also be the major possible causes for the rise of surface temperature in the study area. The result is in agreement with (Kerr et al., 2004; Maitima et al., 2009; Khin et al., 2012; Feyisa et al., 2014 and Samson et al., 2018) that the major factors for increase of LST both in rural and urban areas are land use/land cover changes and unplanned use of land resources (Figure 6).

Results from Figures 6(A), 6(B) and 6(C) showed that the mean land surface temperature of the study area has increased from $27.08^{\circ} \mathrm{C}, 28.25^{\circ} \mathrm{C}$ in 2010 to $31.78^{\circ} \mathrm{C}$ in 2020 . A great variation in surface temperature was observed in areas having dense vegetation, impervious surfaces and lowest altitude. A Northeastern part of the City, particularly, Goba Hiddi Kebele, experiences higher surface temperature with mean LST value of $34.26{ }^{\circ} \mathrm{C}$ in 2020 due to its lower altitude and bare surface. However central parts of the study area showed a decrease in land surface temperature. As it is possible to observe from figure 3, an area covered with dense green spaces experience low surface temperature; whereas, impervious sides experiences high surface temperature. These variations in Land Surface Temperature (LST) could be resulted from the existence of dense vegetation cover and its topographic set up.

Other studies have also shown similar results. For instance; (Samson, 2018; Melkamu, 2019) pointed out that the lowest mean LST was recorded by water body and green vegetation classes. This means that areas with lower vegetation cover are experiencing higher land surface temperature and vice versa. From this it is clear that vegetation has a cooling and regulating effect on the surface temperature of an area. Studies showed that vegetated surface can contribute significantly to human comfort and better health conditions by decreasing the land surface temperature (Gémes et al., 2016; Melkamu, 2019).

\subsubsection{Normalized Difference Built-up Index (NDBI)}

This study clearly shows that the vegetation cover of the study area where decreased due to rapid expansion of different buildings. Therefore, built-up areas are an inducing much surface 
temperature variations. Of the total area, built-up area alone accounted for about $18.87 \mathrm{~km}^{2}$ (13.67\%) in 2000; and $76.4 \mathrm{~km}^{2}$ (55.29\%). Currently, built-up area occupies the largest portion of the city. The central and Northern parts of the city are packed with man-made features which made the temperature to be higher than the surrounding regions (Figure 7). Some other studies also reveal that the sharp decrease of green spaces and rapid increase of built-up areas decline the cooling effect of green spaces (Žuvela-Aloise et al., 2016). High temperature irregularities are comprehensively related with built up land, densely populated areas, and greatly industrialized zones (Xiong et al., 2012, Samson et al., 2018).

\subsection{Correlation of Land Surface Temperature with Built-up and Green Areas}

These two indices were used to examine temperature variations and also determine their relationship with LST. Strong correlations between LST and both urban parameters were found in the study area. A positive correlation was identified between LST and built-up areas with $\mathrm{R}^{2}=$ 0.9276. This shows that the higher the built-up areas, the higher the LST values. The positive correlation found between Normalized Difference Built-up Index (NDBI) and Land Surface Temperature (LST) indicates that built-up area is producing much Land Surface Temperature (LST) variations and is the main contributor in urban heat island (Figure 8). This finding is in agreement with Ermias and Hiwot, (2018) that the effect of the increment of built-up area will result in severe effect of urban heating.

Linear regression is a basic and commonly used type of predictive analysis. The overall idea of regression is to examine two things: predictor variables - in predicting an outcome (dependent) variable (2) variables in particular are significant predictors of the outcome variable, and in what way do they-indicated by the magnitude and sign of the beta estimates-impact the outcome variable. These regression estimates are used to explain the relationship between one dependent variable and one or more independent variables which were computed in SPSS V.23 for the study area (Eq. 1).

$\operatorname{Ln}(Y)=\ln \left(\frac{y}{1-y}\right)=\beta 0+\beta 1 X 1$ p $\beta 2 X 2+\ldots+\beta n X n$ p ui

Where; 
$\mathrm{Y}$ is the predicted probability of the event; $1-\mathrm{Y}$ is the predicted probability of the other decision; $\beta 0=$ Constant; $\beta \mathrm{n}=$ Coefficients of explanatory variables; $\mathrm{Xn}$ is Predictor variables; ui is Error term.

\subsubsection{Normalized Difference Vegetation Index (NDVI)}

The results of NDVI of both 2000 and 2020 showed that northeast and southwest parts of the study area have higher NDVI value. The little values of NDVI were also observed in dense residential areas with less vegetation coverage. Vegetation cover has decreased and nonvegetated area has been increasing gradually over the study period. The average value of NDVI of the year 2000 was reduced by half percent by the year 2020. Relatively, a high value of NDVI in 2020 is observed on the south and south western parts particularly in Bole kebele whereas northeast part i.e. Goba Hiddi Kebele and the rest parts of the study areas have low values of NDVI. By comparing NDVI of the two different periods (2000 and 2020), it is observed that maximum NDVI values was decreased over the study period (Figure 9).

The study shows that $64.54 \mathrm{ha}$ ( $46.71 \%$ ) of the study area in 2000 were covered by NDVI values greater than 0.2 . But in the year 2020 , only $47.84 \mathrm{~km}^{2}(34.62 \%)$ of the study area was covered by the same NDVI class. These confirmed that there has been a dynamic vegetation cover change from one class to the other in the study area. NDVI values between $0.06-0.4$ represent agricultural fields in the surrounding periphery. Patches of dense vegetation cover in the southern and parts of the City show relatively high NDVI values. A number of studies have also shown that NDVI values of river banks and around water bodies experience the higher NDVI values than other classes, owing to the presence of agricultural land (Feyisa et al., 2014; Samson et al., 2018). The NDVI values of the different years showed that there has been a marked vegetation cover change during the study period of 20 years (Table 5).

The results indicated that the high value of NDVI was distributed in the outskirts and in south western parts of the city. For green areas, a negative correlation was identified with Land Surface Temperature (LST) of the study area, i.e. $\mathrm{R}^{2}=-0.9286$. It can be concluded that, if the area is densely vegetated, the LST is found to be lower. Healthy vegetative cover plays a key role in lowering of the surface temperature. The high value of Land Surface Temperature (LST) was detected in built-up areas and bare faces; whereas low surface temperature was found in areas 
covered with vegetation. The decrease in mean patch size may increase LST because a larger, continuous green space produces stronger cool island effects than that of several small pieces of green spaces.

The analyzed Landsat images of 2000 and 2020 indicated that NDVI and LST have indirect relationships. A Low NDVI value has high LST and high NDVI values have low LST. The results of this study showed that NDVI was correlated with LST with statistical significance. This finding is consistent with studies conducted by Chen et al., 2006; and Buyand et al., 2015 which confirmed that there is a negative co-relation between LST and the richness of green spaces measured by NDVI (Figure 10).

Trees and other plants help cool the environment, making green space a simple and effective way to mitigate urban heat island effects. Therefore, the effects of the increase in patch density on LST can be explained by a decrease in mean patch size of green spaces. Generally, negative correlation was found between NDVI values with LST. This finding is in agreement with a number of studies. For instance, (Weng et al., 2004; Zhou et al., 2011; Feyisa et al., 2014;) were show that green spaces can lower surface and air temperatures by providing shade that prevents land surfaces from direct heating from sunlight.

\subsection{Estimation of LST in the Selected Test Spots of Adama City}

Land Surface Temperature (LST), Normalized Difference Vegetation Index (NDVI) and Normalized Difference Built-up Areas (NDBI) were aggregated to $30 \mathrm{~m} \times 30 \mathrm{~m}$ cells for statistical analysis in ArcGIS and Regression analysis was computed in (Statistical Package for Social Science) SPSS V23 software. The scatter plot revealed a negative relationship between Land Surface Temperature (LST) and Normalized Difference Vegetation Index (NDVI) and a positive correlation with Normalized Difference Built-up Index (NDBI) in each of the two years. Through the multiple linear regression analysis, it was found that built-up areas and green areas have significantly affected the LST of Adama City. The model produced through this analysis shows that these two urban parameters contributed for $75.2 \%$ of the LST variations with the $\mathrm{R}^{2}=$ 0.75. Thus, the value of LST in Adama City can be estimated using these two urban parameters

with a reasonable accuracy. The following equation is the model produced in this study to estimate the LST value of Adama City.

$$
\mathrm{LST}=2.4398 \mathrm{x}_{1}+0.1995-38.076 \mathrm{x}_{2}+8.467
$$


Where;

- $\quad$ LST - Land Surface Temperature (LST)

- $\quad \mathrm{X}_{1}$ - built-up area (NDBI value)

- $\quad \mathrm{X}_{2}$ - green area (NDVI value)

Based on the model produced, an increase of $32.8 \%$ of built-up area elevates the value of LST by $1^{0} \mathrm{C}$ whereas an increase of $19.6 \%$ in NDVI value decreases $1^{\circ} \mathrm{C}$ of LST. An increase of $1{ }^{0} \mathrm{C}$ can affect human thermal comfort. Mature green cover needs to be planted and maintained within an area to balance the negative effect of built-up area. This result is in line with (Isa et al., 2017) point out that the two urban parameters (NDVI and NDBI) have significant effects on the LST; and confirmed that built-up areas have greater influence on the LST as compared to the green areas.

The model produced in this study was used to estimate the value of LST within selected test sites in Adama City. From the total of fourteen (14) kebeles in Adama City, Gooba Hiddi kebele experiences extreme LST values because of the main three reasons. Firstly, the absence of vegetation covers, secondly; the topographic set up (low land), and thirdly, due to man-made features like building, roads, canals, bridges with large portion of bare lands. The mean LST of the kebele was found to be higher than other kebeles with mean LST value of $34.26^{0} \mathrm{C}$. Table 6 shows the simulated LST values for Gooba Hiddii kebele based on the built-up and green area percentage. Both parameters were operated by adding 25\%, 50\%, 75\% and $100 \%$ increments of the built-up area and green area of the selected test sites. The increment of built-up area in the selected site will result in severe effect of urban heating whereas the increment of green areas within the selected site is seen to be the most suitable measures to reduce the LST value by about $5.1^{\circ} \mathrm{C}$. Estimated LST value if both parameters are increased by $25 \%, 50 \%, 75 \%$ and $100 \%$ of the current built-up area and green spaces in selected test spot (Gooba Hiddii Kebele) is shown in (Figure 11).

\subsubsection{Regression Analysis for Land Surface Temperature in Adama City}

The independent variables can be called exogenous variables, predictor variables. Normalized Difference Vegetation Index and Normalized Built-up Index were predictor variables for Land Surface Temperature (LST) distribution in Adama City (Table 7). 
The result clearly reveals that NDBI is a better predictor of LST compared to NDVI. The values in Table17 indicate that built-up density is a better predictor of land surface temperature and has a stronger relationship than NDVI. The adjusted $\mathrm{R}^{2}$ value for both parameters was $72.5 \%$. This shows that the model produced through multiple linear regression analysis clearly indicates that the two urban parameters (built up and green areas) contributed $75.2 \%$ of the LST variations in Adama City (Appendix I). This means that areas with lower vegetation cover are experiencing higher land surface temperature and vice versa. Other studies have also shown similar results (Weng et al., 2004; Effat, 2014; Ermias and Hiwot, 2018). Table 8 shows the summary statistics

of the relationship among LST, NDBI, NDVI and Elevation corresponding to kebeles in Adama city.

\subsection{Cooling Effects of Urban Green Space}

The cooling efficiency is expressed as a logarithmic curve between the area of each Urban Green Spaces (UGS) and its maximum Change in Land Surface Temperature ( $\triangle$ LST). Variations in land surface temperature and cooling efficiency of green spaces in Adama City has evaluated. Areas of green spaces patches are in logarithmic relationship with the maximum temperature difference with coefficient correlation of $\left(\mathrm{R}^{2}=0.6922\right)$. This demonstrates that the areas of green spaces are highly associated with the cooling range and maximum surface temperature difference. Based on the statistics of the cooling range appropriate to the areas of the green spaces, a regression analysis of the area with cooling extent and maximum surface temperature difference respectively was made (Figure 12).

The threshold was assessed by computing the difference in temperature between inside the green space and the average land surface temperature of the entire landscape of the city.

The range of $5.5 \pm 0.5$ ha can bring change on surface temperature by about $2.85^{\circ} \mathrm{C}$. This indicate that the bigger the size of green space, the higher the cooling efficiency of green space patches. The inclination of the model curve is very steep on the left hand side which means that the cooling efficiency of green space increase with the size of green spaces sharply. On the right hand side, the gradient is low and the cooling efficiency is become reduced and stable. Threshold value of the cooling Efficiency of green space is then calculated as (TVoE $=5.50 \mathrm{ha}$ ).

The formula of the cooling efficiency curve of green space is $\mathrm{y}=0.6641 \ln (\mathrm{x})+1.5997\left(\mathrm{R}^{2}=\right.$ 0.6922). This turning point is the maximum Land Surface Temperature change ( $\Delta$ LST) and defined as the cooling intensity of urban green spaces. 
In this study, to further validate the results, the size of green space patches were divided into three segments ( $<1$ ha, $1-4$ ha, $2-4$ ha and greater than 5 ha. The results indicate that in the $0-5$ ha segments, correlations between $\Delta \mathrm{LST}$ and the size of green space show a positive relationship, which changes to a negative relationship in the 5ha segment. This study validates that the calculated Threshold Value of Efficiency (TVoE) in this study is consistent.

The TVoE of the study clearly shows that smaller green spaces have a positive relation with change in Land Surface Temperature (LST), but green space with an area greater than $5.5 \pm$ 0.50 ha have a negative relation with LST change. Some studies also revealed that the cooling effect of green spaces have size-based threshold value. For instance, Chen et al., (2012) pointed out that 5ha of green space area is a vital onset value for cooling. Zhaowu (2018) also indicated that $4.55 \mathrm{ha}$ of green space area is an important threshold value for cooling; and agreed that the maximum cooling extent of Urban Green Spaces (UGS) is stated as the distance between the edge of the vegetation cover and the first turning point of temperature drop compared with the urban green space temperature. 


\section{Conclusion}

In this research efforts have made to analyze the cooling effects of green spaces. Relationship of surface temperature with green and non-green areas was analyzed. The Land Surface Temperature (LST), Normalized Difference Vegetation Index (NDVI) and Normalized Difference Built-up Index (NDBI) were generated from Landsat7 ETM+ and Landsat 8 OLI/TIRS which were used to generate important information on LU/LC for the determination of the cooling effects of green spaces in mitigating urban micro-climate change in Adama City using Geospatial techniques. The correlation between Land Surface Temperature (LST) and the two urban parameters (built up area and green space) were assessed. A positive correlation value identified between LST and built-up areas with $\mathrm{R}^{2}=0.9276$. This reflects that the higher the built-up areas, the higher the LST values. It shows that built-up area is producing much land surface temperature. Additionally, the differences of temperature between the areas covered with vegetation and their surroundings indicate that vegetation can minimize surface temperature. The rise of LST in the City was mainly resulted from rapid expansion of the built-up areas and deterioration of vegetation cover. The Normalized Difference Vegetation Index (NDVI) of the year 2000 having the value $>0.2$ was reduced from an area of $64.54 \mathrm{~km}^{2}(46.71 \%)$ to $47.84 \mathrm{~km}^{2}$ (34.62\%) in the year 2020. It clearly shows that expansion of built-up land has caused significant land cover change (LCC). Rapid expansion of the built-up areas and deterioration of vegetation cover are the two most important deviations which could be a major possible cause for urban heat island effect in Adama City. It is believed that the study has potential to contribute to our understanding of how urban green spaces can mitigate micro-climate change so that the environmental problems may be resolved.

Generally, the study provides insight regarding the importance of valuing the effectiveness of urban green spaces in mitigating micro-climate change. In this study, value of the types, species, shape and forms of green spaces in mitigating micro-climate did not considered separately. Therefore, further study need to be carried out through incorporating additional factors for a better understanding on the cooling efficiency of green spaces in mitigating urban micro-climate changes. 


\section{Ethical statement}

Hereby, Biratu Bobo Merga, corresponding author for the manuscript entitled as "Analysis of the Cooling Effects of Urban Green Spaces in Mitigating Micro-Climate Change Using Geospatial Techniques in Adama City, Central Ethiopia" assure you that the manuscript has not been previously published or under consideration for publication elsewhere. All secondary information is correctly acknowledged through citations. All authors contribute and approved the final draft.

Authors' Contributions: Biratu Bobo Merga involved in data collection, literature work, data analysis and manuscript writing. Kenate Worku Tabour and Girma Alemu were also engaged in providing critical comments and approved final manuscript.

Funding: No funding received for this research.

Data availability: Available in this manuscript.

Conflict of interest: The authors declare no competing interest.

Ethics Approval and Consent to Participate: Not applicable.

Code availability: Not applicable

Consent for Publication: The authors agreed to publish the manuscript on Journal of Theoretical and Applied Climatology 


\section{References}

Avdan, U. and Jovanovska, G. (2016). Algorithm for Automated Mapping of Land Surface Temperature Using Landsat 8 Satellite Data. Journal of Sensors. 2016:1-8. Article ID 1480307. http://dx.doi.org/10.1155/2016/1480307.

Bhatta, B. (2008). Remote sensing and GIS: Oxford University Press, USA.

Buyadi, S. N. A., Mohd, W. M. N. W. and Misni, A. (2015). "Vegetation's Role on Modifying Microclimate of Urban Resident", Procedia - Social and Behavioral Sciences. Elsevier B.V., 202(December 2014), pp. 400-407. doi: 10. 1016/j.sbspro.2015.08.244

Chander, G., and Markham, B., (2003). Revised Landsat-5 TM radiometric calibration proceduresand post calibration dynamic ranges. IEEE Trans. Geosci. Remote Sens. 41 (11), 2674-2677.

Central Statistical Authority (CSA) Adama Branch. (2009). Population and housing census of Ethiopia: Results for Adama City. Adama, Ethiopia.

Chen, X. L., Zhao, H. M., Li, P. X. and Yin, Z. Y. (2006). Remote sensing image based analysis of the relationship between urban heat island and land use/cover changes. Remote Sensing of Environments, 104: 133-146.

Chen, X., Su, Y., Li, D., Huang, G., Chen, W., and Chen, S. (2012). Study on the cooling effects of urban parks on surrounding environments using landsat tm data: A case study in guangzhou, southern china. Int. J. Remote Sens. 5889-5914.

Choi, H., Lee, W., and Byun, W. (2012b). Determining the Effect of Green Spaces on Urban Heat Distribution Using Satellite Imagery. Asian Journal of Atmospheric Environment, 6(June), 127-135. doi:http://dx.doi.org/10.5572/ajae.6.2.127

Cohen, P., Potchter, O., and Matzarakis, A. (2013). Human thermal perception of coastalMediterranean outdoor urban environments. Applied Geography, 37, 1-10.

Dagnachew, Sisay. (2018). Remote sensing and GIS approach for estimation of land surface temperature to examine urban heat island effect on a city scale; The Case of Hawassa city, Ethiopia (Un published)

Effat, H. A., Taha, L. G., and Mansour, K. F. (2014). Change Detection of Land cover and Urban Heat Islands Using MultiTemporal Landsat Images, Application in Tanta City, Egypt. Open Journal of Remote Sensing and Positioning, 1(2):1-15. 
Ermias, Teferi., and Hiwot. (2018). Urban Heat Island Effect of Addis Ababa City: Implications of Urban Green Spaces for Climate Change Adaptation. Research Gate.

Feyisa, GL., Dons, K., and Meilby, H. (2014). Efficiency of parks in mitigating urban heat island effect: An example from Addis Ababa. Landscape and Urban Planning, 123, 87-95.

Foody, G. M., Campbell, N. A., Trodd, N. M., and Wood, T., F. (1992). Derivation and applications of probabilistic measures of class membership from the maximum-likelihood classification. Photogrammetric Engineering and Remote Sensing, 58(9), 1335-1341.

Gandhi, GM., Parthiban, S., Thummalu, N., and Christy, A. (2015). NDVI: Vegetation change detection using remote sensing and GIS-A case study of Vellore district. Procedia Computer Science 57: 1199-1210.

Gémes, O., Tobak, Z., and Van, Leeuwen., B. (2016). Satellite based analysis of surface urban heat island intensity. Journal of Environmental Geography, 9: 23-30.

IPCC, (2014). Climate Change Impacts, Adaptation and Vulnerability: Regional Aspects. Cambridge University Press

Kerr, YH., Lagouarde, JP., Nerry, F., and Ottle, C. (2004). Land surface retrieval techniques and applications: case of AVHRR. In: Quatrocci DA, Luvall JC Thermal remote sensing in land surface processes. CRC press, Florida, pp 33-109

Khin, MY., Shin, DY., Park, JJ., and Choi, CC. (2012). Land surface temperature changes by LU changes of Inlay Lake area, Myanmar. Department of Spatial Information Engineering, Pukyong National University, South Korea

Kong, F., Yan, W., Zheng, G., Yin, H., Cavan, G., Zhan, W., Zhang, N., and Cheng, L. (2016). Retrieval of three-dimensional tree canopy and shade using terrestrial laser scanning (TLS) data to analyze the cooling effect of vegetation. Agric. For. Meteorol., 217, 22-34,

Kshama, Gupta. (2012). Urban Neighborhood Green Index - A measure of green spaces in urban areas. Landscape and Urban Planning 105 (2012) 325-335

Maitima, JM., Mgatha, SM., Reid, RS., Gachimbi, LN., Majule, A., Lyaru, H., Pomery, D., Mathai, S., and Mugisha, S. (2009). The linkage between landuse change, land degradation and biodiversity across East Africa. Afr J Environ Sci Technol 3:310-326

Melkamu and Meseret. (2019). Analysis of Spatio-temporal Land Surface Temperature and Normalized Difference Vegetation Index Changes in the Andassa Watershed, Blue Nile Basin, Ethiopia. Journal of Resources and Ecology Vol. 10 No.1 
Ngom, R., Gosselin, P., Blais, C., (2016). Reduction of disparities in access to greens paces: their geographic insertion and recreational functions matter. Appl. Geogr. 66, 35-51,

Nor, S. (2013). "Green Spaces Growth Impact on the Urban Microclimate", 105, pp. 547-557. doi: 10.1016/j.sbspro.2013.11.058

Nuruzzaman, M. (2015). Urban Heat Island: Causes, Effects and Mitigation Measures-A Review International Journal of Environmental Monitoring and Analysis, 3(2), 67.

Pervaiz, S., Shirazi, A. S., Khan, F. Z., Javid, K., and Aziz, M., T. (2018). Tree census of urban green space with special reference to Gora cemetery of Lahore, Pakistan. International Journal of Biosciences, 13(1), 431-439

Qin, Z. H., Li, W. J., Zhang, M. H., Arnon, K., and Pedro, B. (2003). Estimating of the essential atmospheric parameters of mono-window algorithm for land surface temperature retrieval from landsat TM6. Remote Sens. Land Resource. 2 (56),

Roza, A., Suryabhagavan, K. V., Balakrishnan, M., and Hameed, S. (2017). Geo-spatial approach for urban green space and environmental quality: A case study in Addis Ababa city. Journal of Geographic Information System 9: 191206

Samson, Warkaye., Suryabhagavan, K. V., and Satishkumar, B. (2018). Urban Green Areas to Mitigate Urban Heat Island Effect: The Case of Addis Ababa, Ethiopia. International Journal of Ecology and Environmental Sciences 44 (4): 353-367, 2018

Sandra, O., Henrique, A., and Teresa, V. (2011). "The Cooling Effect of Green Spaces as a Contribution to the Mitigation of Urban Heat: A Case Study in Lisbon." Building and Environment 46: 2186-2194.

Senanayake, I. P., Welivitiya, W. D. D. P., and Nadeeka, P., M. (2013). Remote Sensing Based Analysis of Urban Heat Islands with Vegetation Cover in Colombo city, Sri Lanka using Landsat-7 ETM+ data. Urban Climate. doi:10.1016/j.uclim.2013.07.004

Sobrino, J. A., Rosa, O., Guillen, S., Juan, C. J., Belen. F. Victoria. H., Cristian, M., ～Yves, J., Juan, C., Mireia, R., Antonio, G. J., Eduardo, D. M., Remo, B., and Marc, p. (2012). Evaluation of the surface UHI effect in the city of Madrid by thermal RS. International journal of remote sensing, 34, 910

Yu, X., Xulin, Guo., and Zhaocong, Wu. (2014). Land Surface Temperature Retrieval from Landsat 8 TIRS Comparison between Radiative Transfer Equation-Based Method, Split Window Algorithm and Single Channel Method, Remote Sens. 6:9829-9852. 
Zhaowu, Yu., Xieying, Guo., Yuxi, Zeng., Motoya, Koga., Henrik, Vejre. (2018). Variations in land surface temperature and cooling efficiency of green space in rapid urbanization: The case of Fuzhou city, China. Urban Forestry \& Urban Greening. 29 - 113-121

Zhong, L., Su, Z., and Ma, Y. (2011). Accelerated changes of environmental conditions on the Tibetan Plateau caused by climate change. J. Clim. 24 (24), 6540-6550,

Zhou, Y., Yang, G., Wang, S., Wang, L., Wang, F., and Liu, X. (2014). A new index for mapping built up and bare land areas from Landsat8 OLI data. Remote Sensing Letters, $5(10)$

Žuvela-Aloise, M., Koch, R., Buchholz, S., and Früh, B. (2016). Modelling the potential of green and blue infrastructure to reduce urban heat load in the city of Vienna. Clim. Change 114. 
Figures

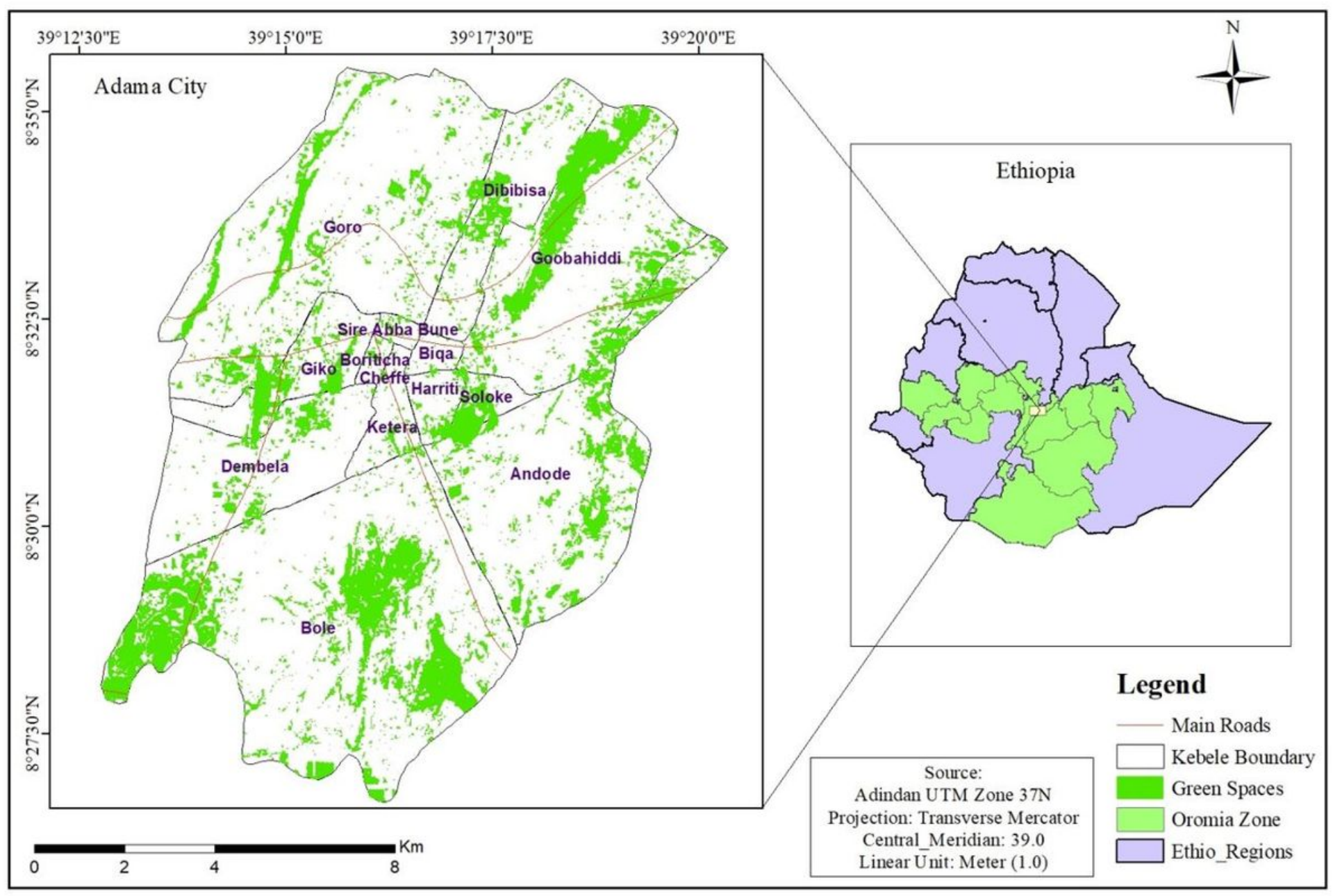

Figure 1

Location Map of Adama City (Extracted from EthioGIS, 2014) 


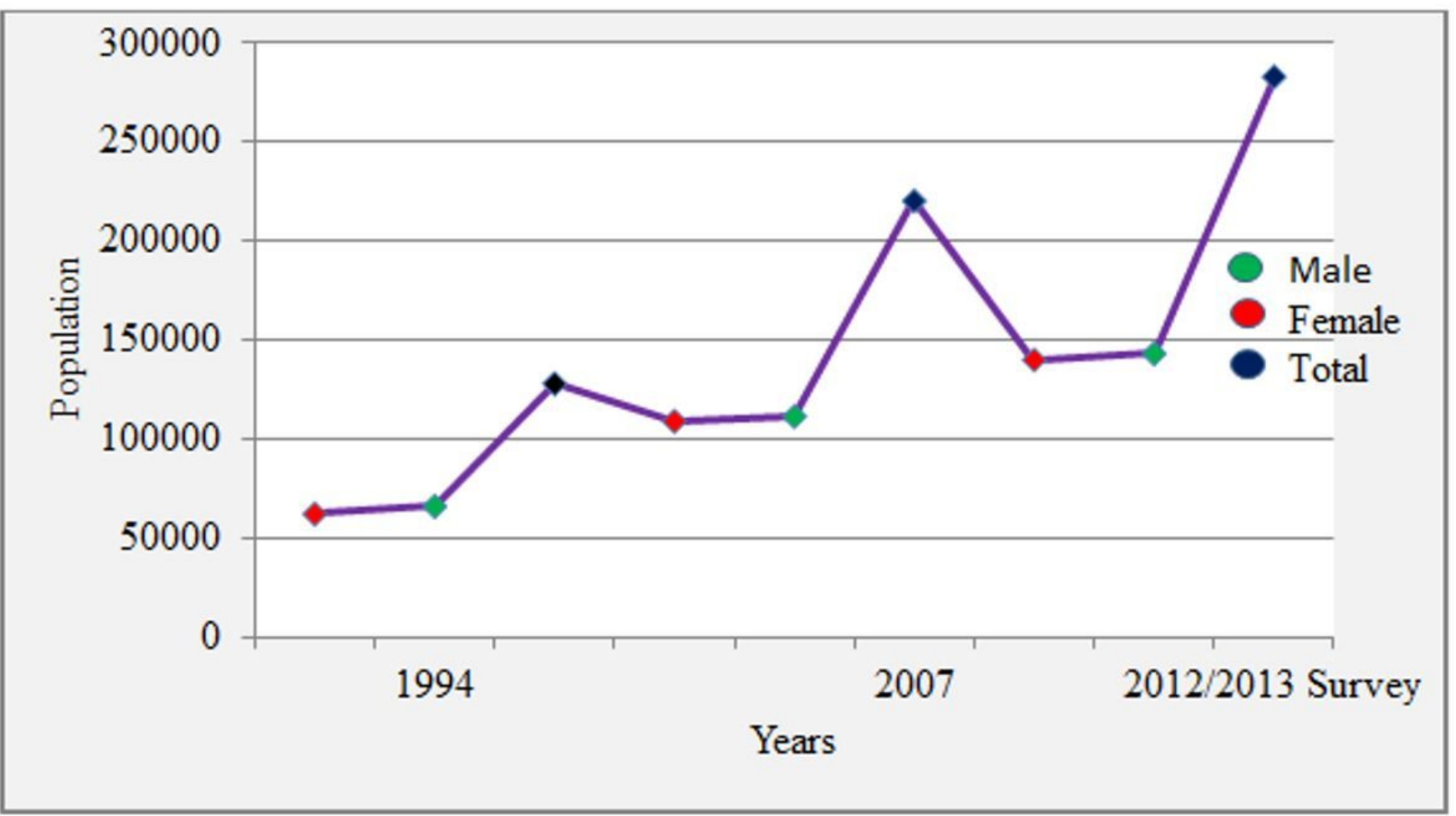

Figure 2

Population of Adama City

(Source: Adama City Statistics Office, 2013) 




Figure 3

Data set and Work Flow Diagram 


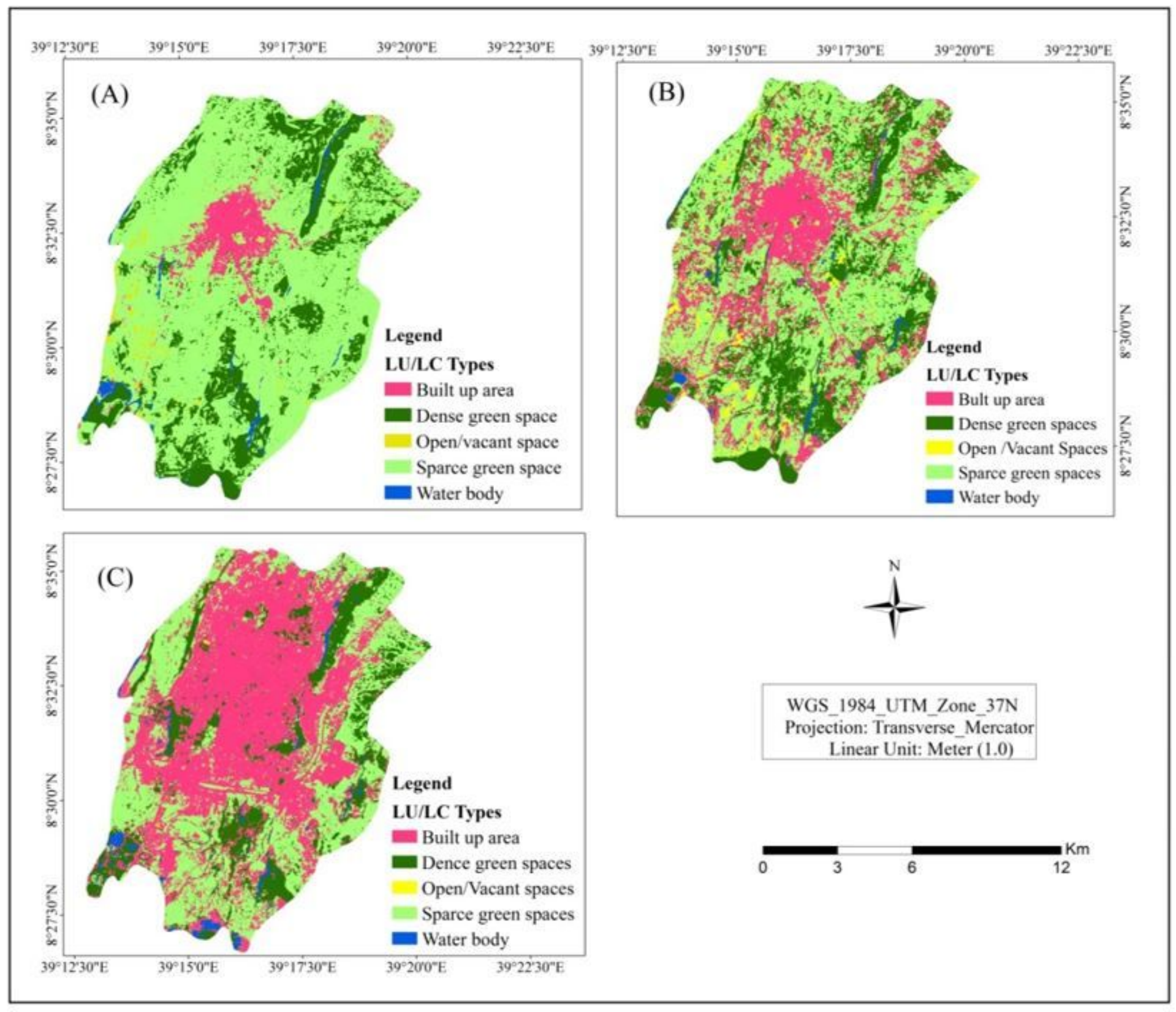

Figure 4

LU/LC maps of the year 2000 (A), 2010 (B) and 2020(C) 


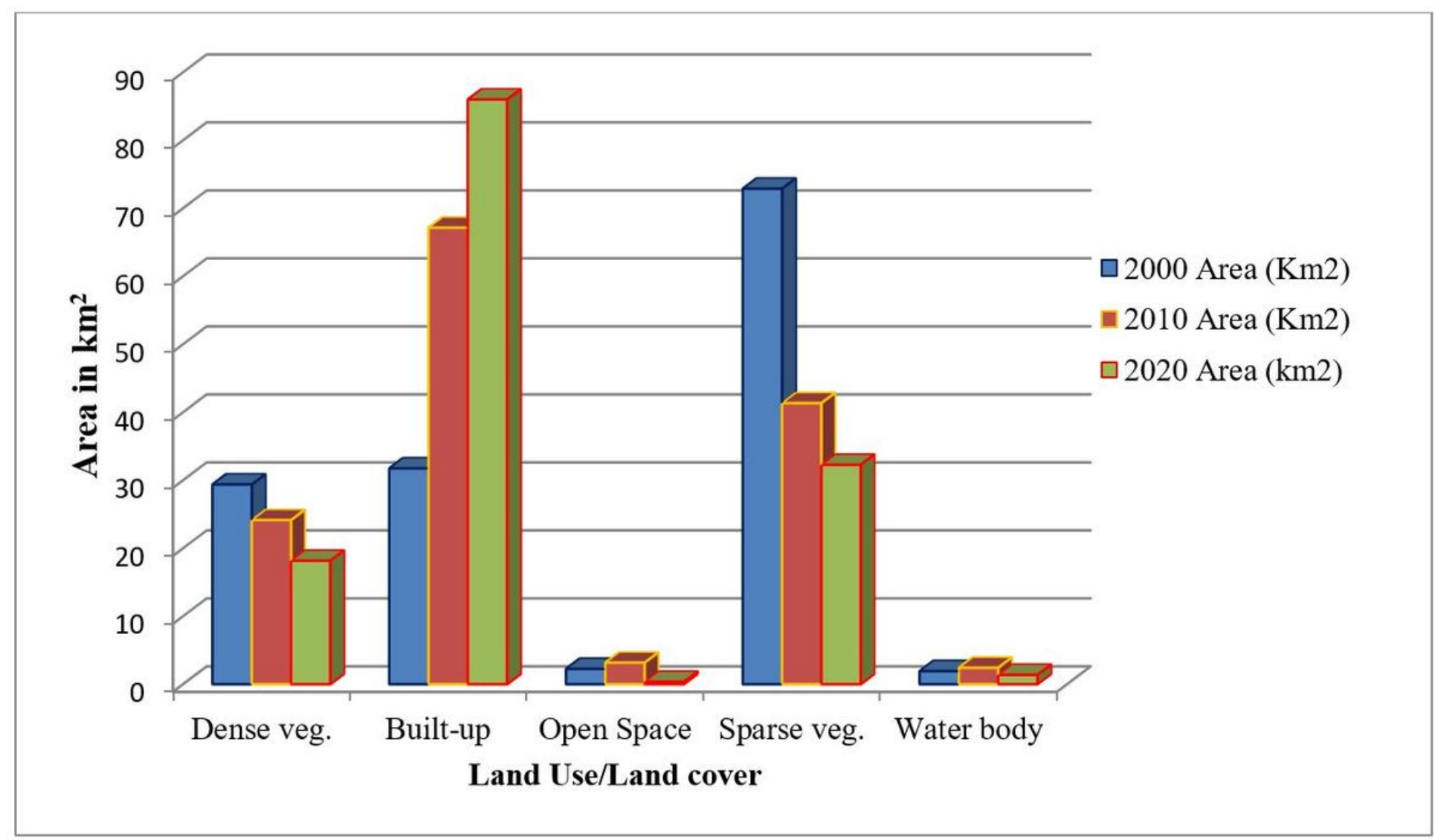

Figure 5

LU/LC of the Year 2000, 2010 and 2020 

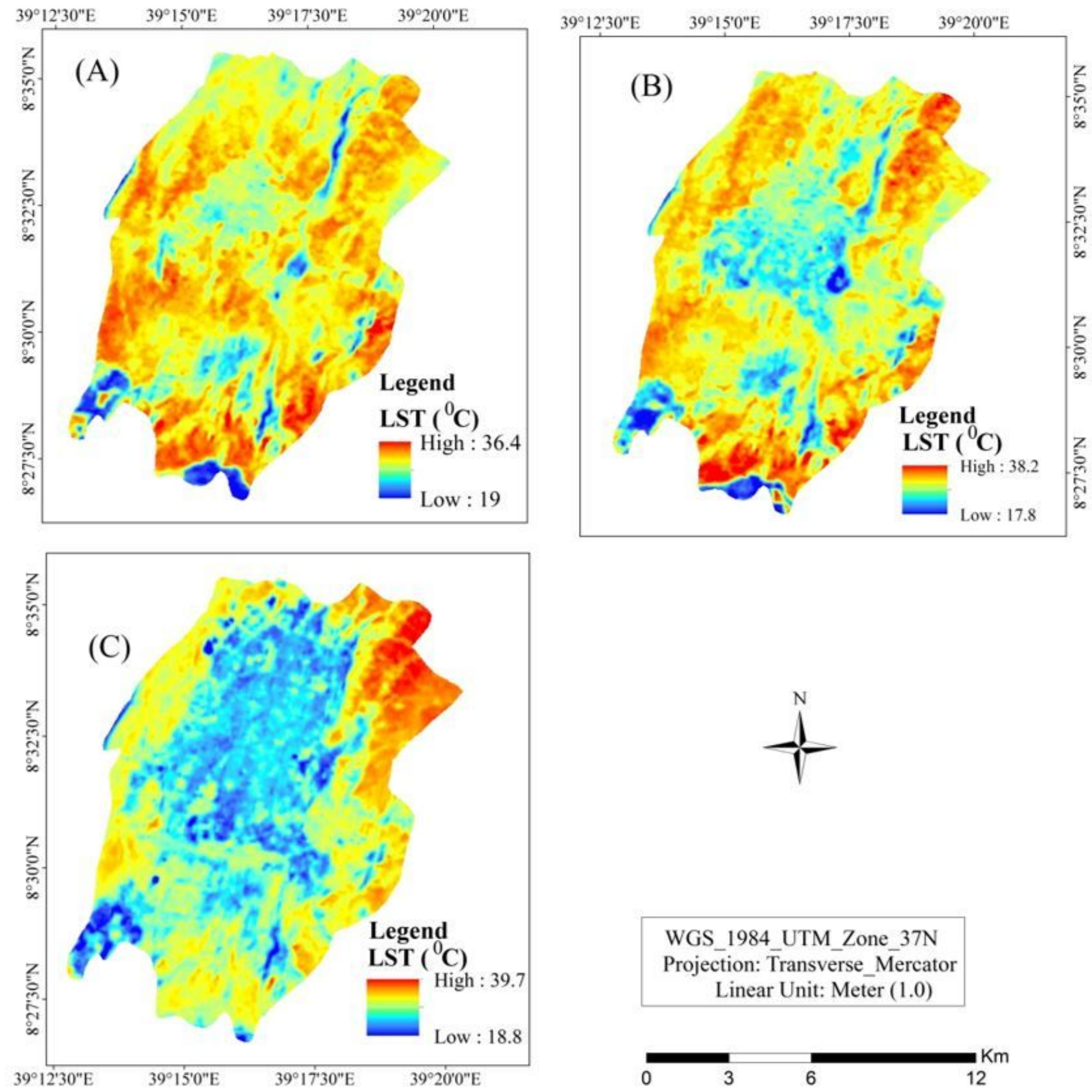

\section{Figure 6}

LST Map of the year 2000(A) and 2010(B) and 2020(C)

WGS_1984_UTM_Zone_37N

Projection: Transverse Mercator Linear Unit: Meter (1.0)

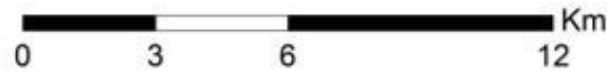




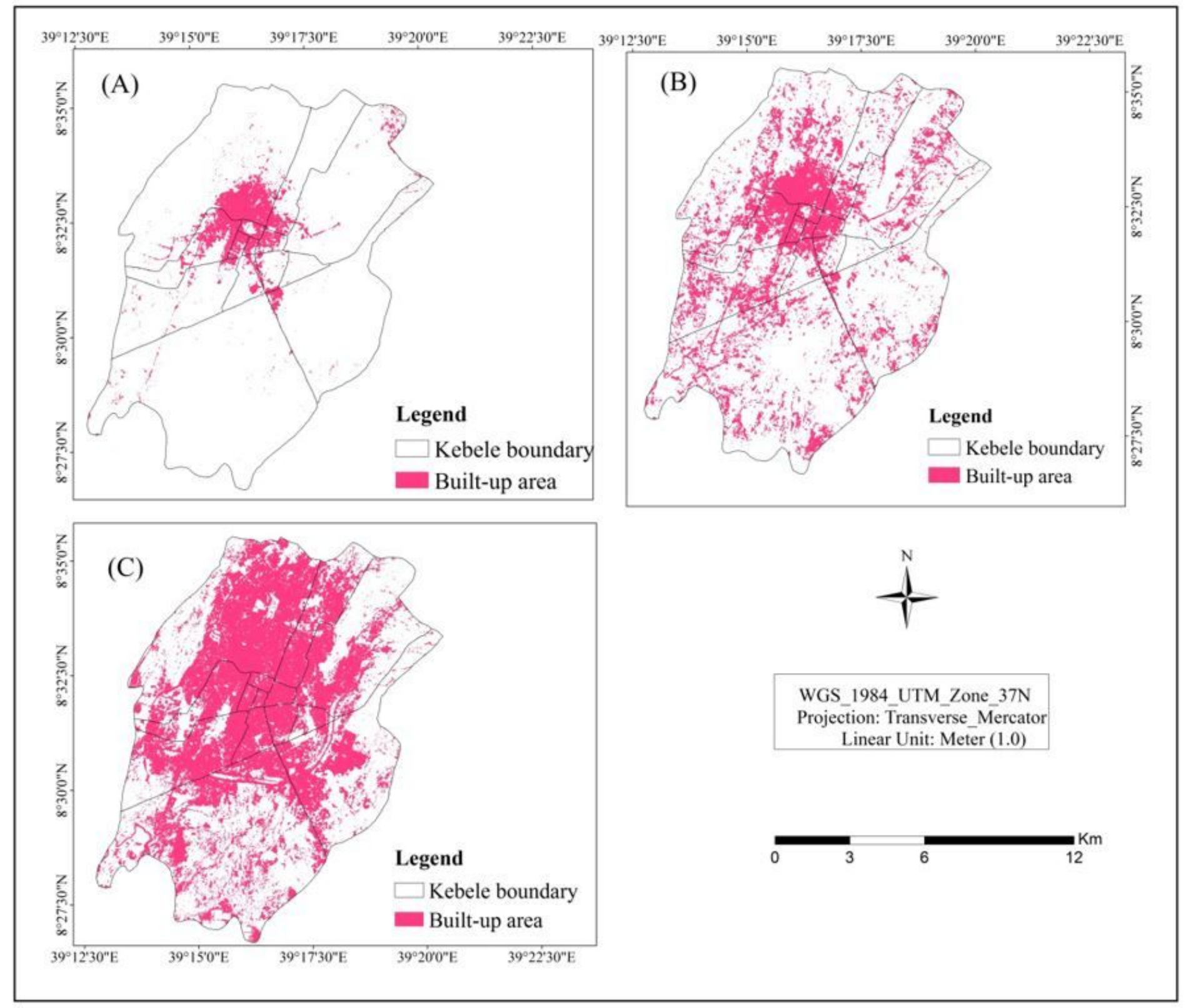

Figure 7

Built-up Areas of Adama City in 2000(A), 2020(B) and 2020(C) 


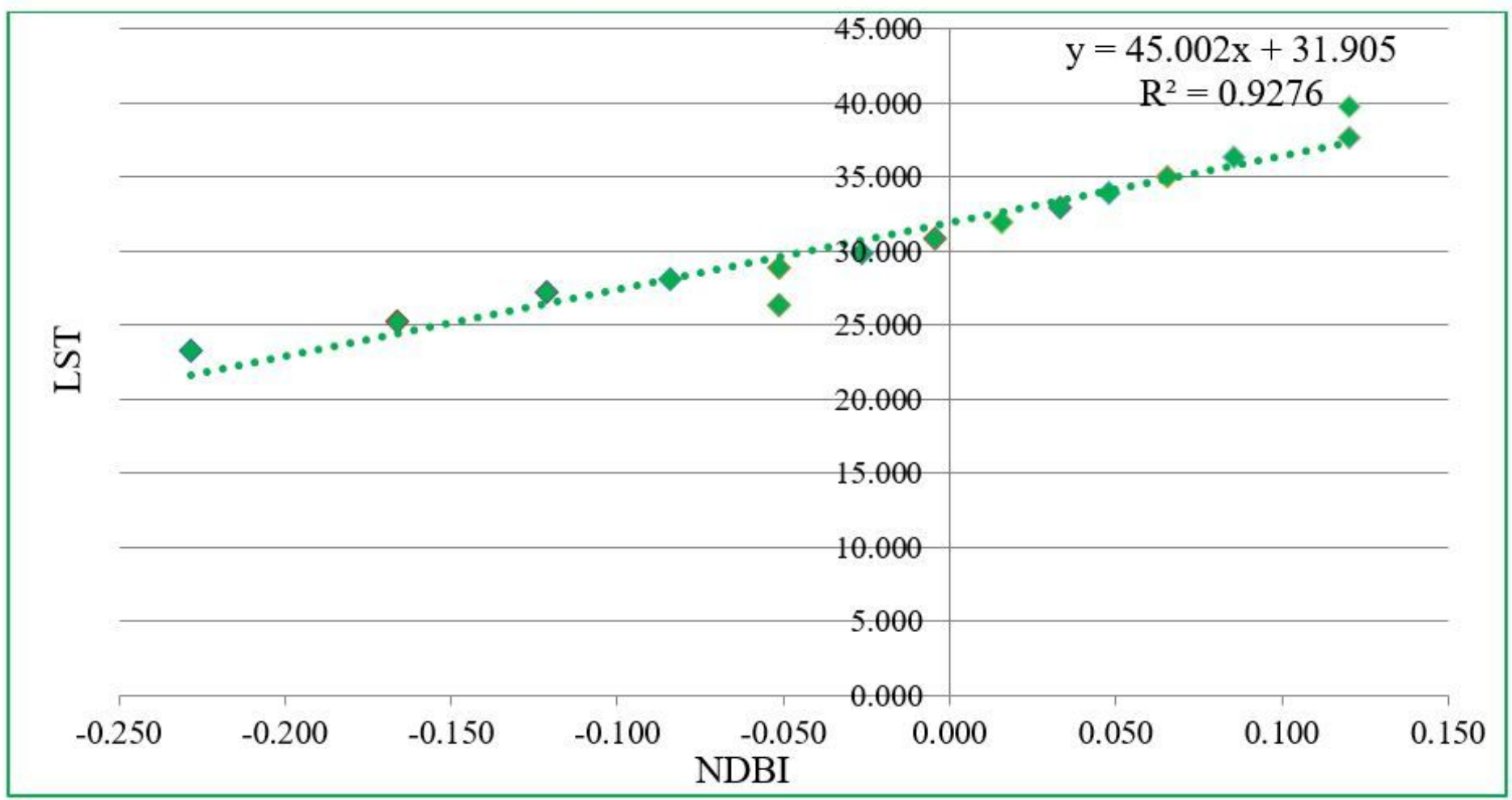

Figure 8

Relationship between LST and NDBI 


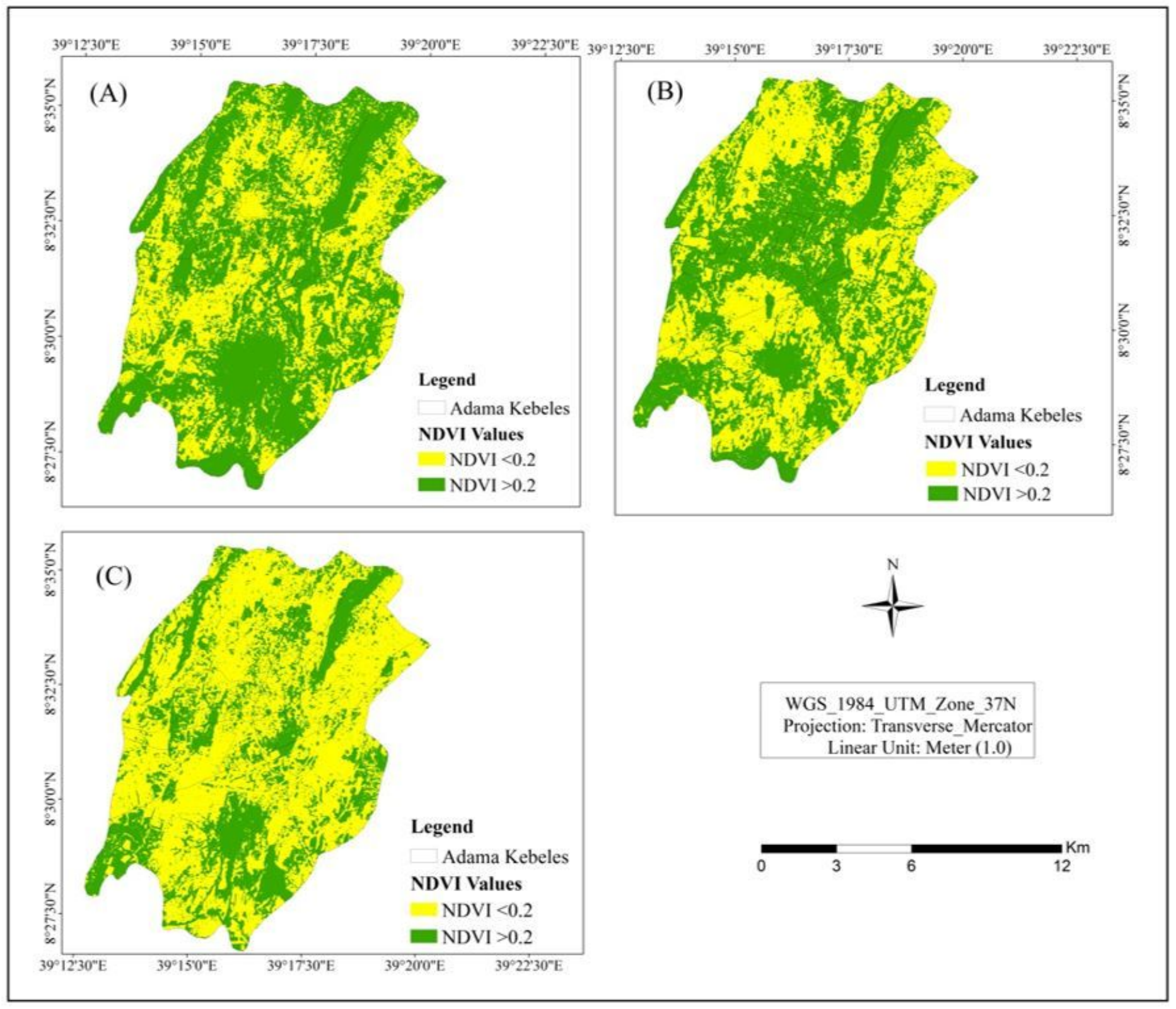

Figure 9

Normalized Difference Vegetation Index results for the year 2000(A), 2010(B) and 2020(C) 


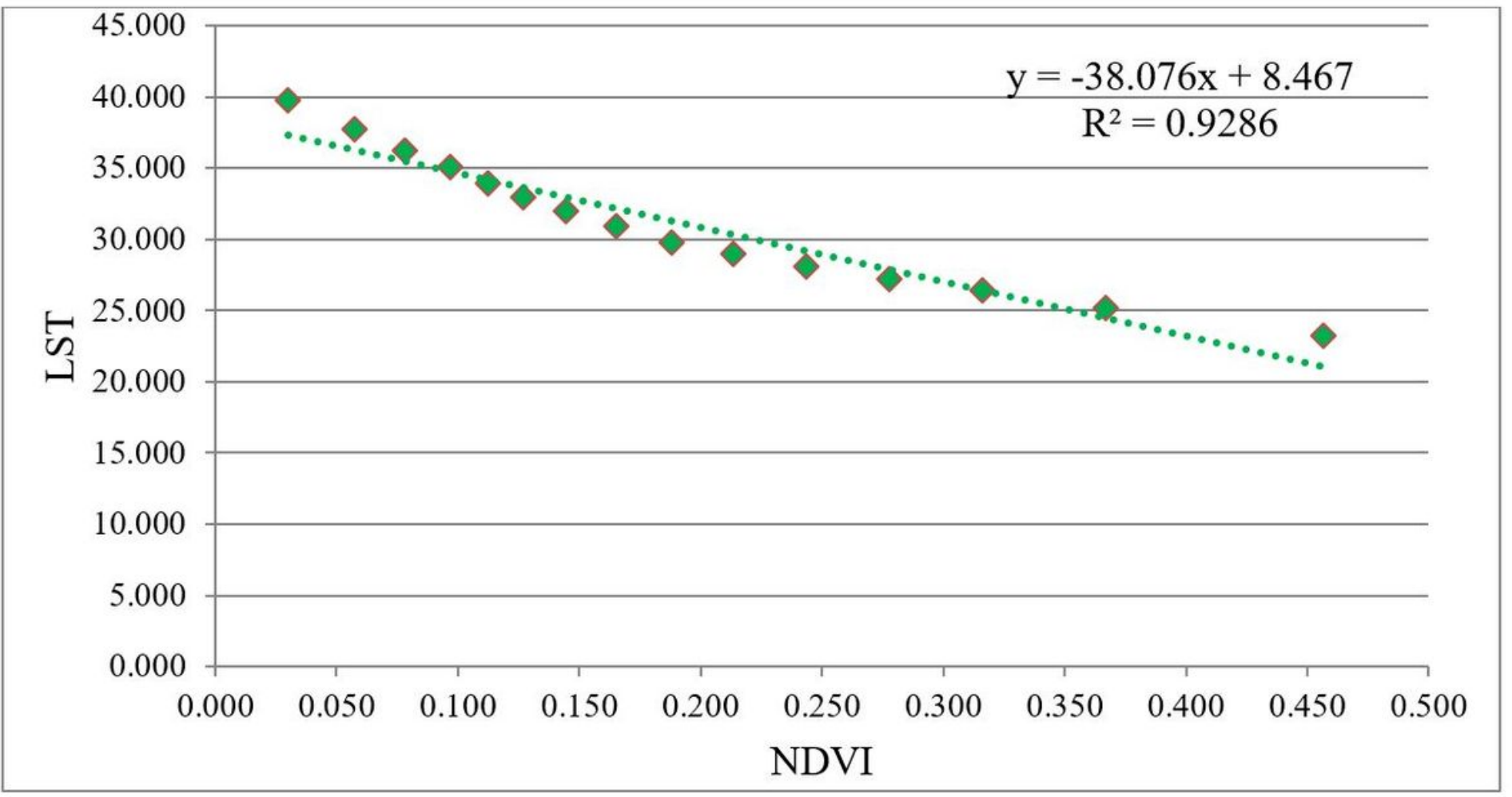

Figure 10

Relationship between LST and NDVI

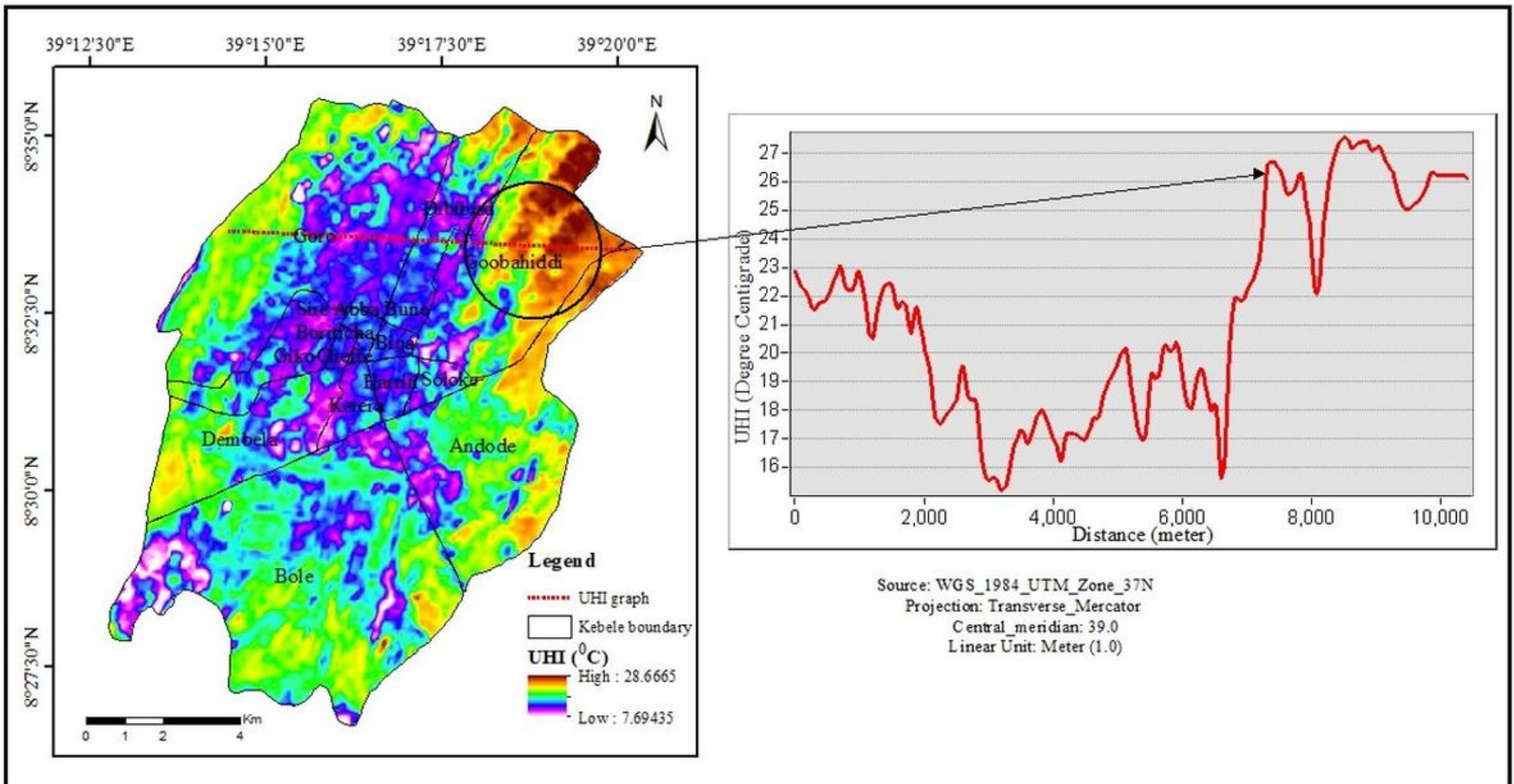

Figure 11 
Estimation of LST in the Selected Test Spot in Adama City

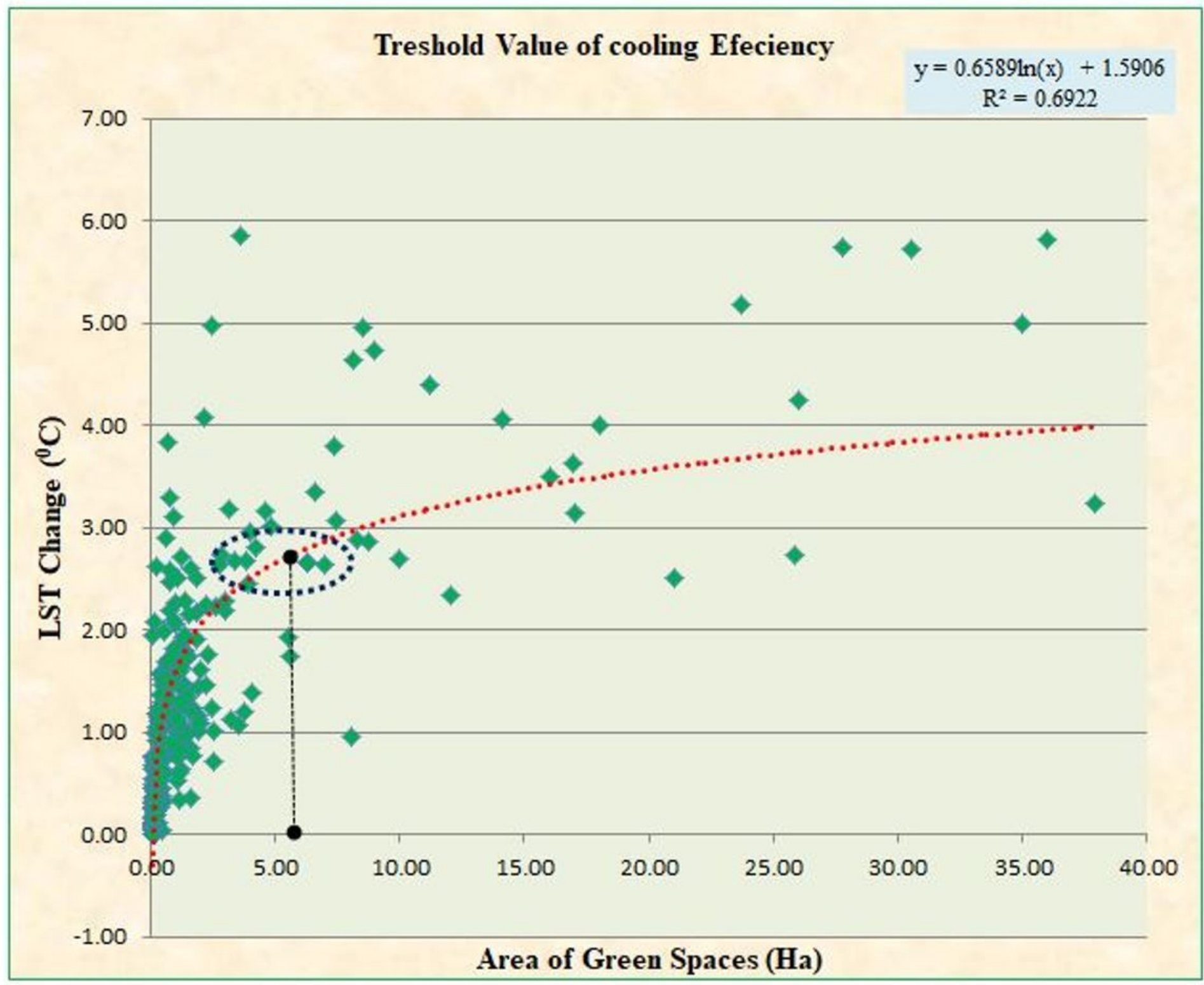

Figure 12

Threshold value of cooling efficiency 